also throws doubt on the theory that all colour combinations take place in a single locus of the brain, and not in the retina. It is more likely that comple. mentaries combine in the eye, though neighbouring colours may combine in the brain.

Psychology Department,

R. W. PICKFORD

University, Glasgow.

$$
\text { Jan. } 1 .
$$

'Walls, G. L., "The Vertebrate Eve", 90 (1942).

'Walls, G. L., "The Vertebrate Eye", 331-38 (1942).

sBurt, C., "Factors of the Mind" (1940).

\section{Social Science in the Gap between the Royal Society and the British Academy}

To which of the two above-named august institutions should research workers in social science look up for recognition, guidance, grants-in-aid, expert criticism, and publication? The recent Clapham Report ${ }^{1}$, on the Provision for Social and Economic Research, was drawn up by a committee of nine whose qualifications included three F.B.A., three Litt.D., two Ll.D., one D.Se., but no F.R.S. This literary preponderance suggests that the appropriate body is the British Academy. But a surer guide is a comparison of publications. Those of the British Academy, though full of literary grace and social interest, scarcely contain any quantitative analysis. I doubt if a correlation coefficient could be found anywhere among them. An article in celebra. tion of Leibniz ${ }^{2}$ does not contain any mathematical symbols. On the other hand, the publications of the Royal Society, though full of quantitative analysis, scarcely contain any direct mention of human social relations. To which body should a quantitative analysis of a social problem, therefore, be offered for publication? Apparently to neither. There is thus an awkward gap at the highest level of authority. No such gap was intended when the British Academy was formed ${ }^{3}$ in 1902. One of its presidents, Sir Frederic Kenyon, in his presidential address on July 4, 1918, said of academies of learning : "Their normal formation is in two classes, one comprising what we now commonly call humanistic studies, i.e., history, philosophy and philology (in the widest sense of the latter term), the other mathematics and natural science.... In this country the Royal Society corresponds to one of these classes. The British Academy was founded to play the other part." Since 1902 social science, like other sciences before it, has become more statistical, more quantitative, more mathematical. To give only one example: there are now many published researches on the intelligence of school-children, and on its correlations with their parentage and other social conditions. The results are important for planning, and their discussion involves matrix algebra ${ }^{4}$. So a gap, unsuspected in 1902, has now opened wide. Fortunately the gap is bridged by a number of specialized societies and journals publishing severally statistics, psychology and economics. In the history of science some of the papers printed in specialized journals have turned out to be quite as important as those printed by the Royal Society; for example, Karl Pearson's $\chi^{2}$ test appeared in the Philosophical Magazine for 1900. Nevertheless, a gap remains, because the specialized societies lack the breadth and the general authority of the senior bodies.

I have here emphasized only one of the aspects of a problem which has been explored in general by a Committee ${ }^{5}$ on Scientific Research on Human Institutions appointed by the British Association. Reference should also be made to the review of the Clapham Report by Prof. P. Sargant Florence.

Hillside House,

Kilmun, Argyll. Dec. 31 .

${ }^{1}$ H.M. Stationery Office. Cmd. 6868 .

- Proc. Brit. Acad., 23, 193.

" "Encyclo. Brit.", fourteenth edition, 1, 85 (1929).

- Thomson, Godfrey H., Presidential Address to the British Psychological Society, 1946 (University of London Press). - The Advancement of Science, 2, 345 (1943).

- Nature, 158, 368 (1946).

Relationships between the Assemblages of Plants Fed Upon by Different Insects, and between the Assemblages of Insects that Feed Upon Different Plants

IN the course of a recent investigation of the foodplants of the Chrysomelidæ, a family of about 27,000 species of phytophagous beetles, I have tabulated all available records in relation to the systematic groups simultaneously of the beetles and of the food-plants concerned. The results of this investigation have not yet been published, but they lead me to consider that it would be of interest to investigate the extent to which the following propositions are true for insects in general :

If insects of any given species can feed on plants of more than one species, then insects of any other species that can feed on any of these plant species can feed on all these plant species.

If plants of any given species are fed upon by insects of more than one species, then plants of any other species that can be fed upon by any of these insect species can be fed upon by all these insect species.

A priori, these propositions are suggested by analogy. It is at once apparent that they cannot be true without exception, if only because it is known that changes in food-habit are possible in Nature. Moreover, it is an empirical fact that exceptions are observed. Nevertheless, my work on the foodplants of the Chrysomelidæ indicates that these propositions contain a sufficiently large element of truth to be of service in this family as standards for comparison, as bases for prediction, and as indications of possible directions for further observation.

I should welcome the comments of other workers on the extent to which these generalizations are found to be valid and useful in other groups of insects.

S. MaULIK

British Museum (Natural History), London, S.W.7.

Jan. 3 .

\section{Allometry of the Vertebrate Brain}

Fifry years ago, Dubois ${ }^{1}$ investigated the relationship between the brain and body-weights of certain mammals. Continuing the work of Snell ${ }^{2}$, he adopted an expression of the form

$$
y=b x^{\alpha}
$$

to describe this relationship, where $x$ is body weight, $y$ is brain weight and $\alpha$ and $b$ are parameters to be determined from the observations; $\alpha$ was termed the phylogenetic constant and $b$ the cephalization constant. 